\title{
Food availability limits avian reproduction in the city: An experimental study on great tits Parus major
}

\author{
Gábor Seress $^{1}$ (i) | Krisztina Sándor ${ }^{2}$ (D) | Karl L. Evans ${ }^{3}$ (D) | András Liker ${ }^{1}$ (D)
}

${ }^{1}$ MTA-PE Evolutionary Ecology Research Group, University of Pannonia, Veszprém, Hungary

${ }^{2}$ Department of Limnology, University of Pannonia, Veszprém, Hungary

${ }^{3}$ Department of Animal and Plant Sciences, University of Sheffield, Sheffield, UK

\section{Correspondence}

Gábor Seress

Email: seressg@almos.uni-pannon.hu

\section{Funding information}

National Research, Development and Innovation Office, Grant/Award Number: K112838 and PD 120998; Hungarian Ministry of Human Capacities, Grant/Award Number: 1783-3/2018/FEKUSTRAT

Handling Editor: Elizabeth Derryberry

\section{Abstract}

1. The altered ecological and environmental conditions in towns and cities strongly affect demographic traits of urban animal populations, for example avian reproductive success is often reduced. Previous work suggests that this is partly driven by low insect availability during the breeding season, but robust experimental evidence that supports this food limitation hypothesis is not yet available.

2. We tested core predictions of the food limitation hypothesis using a controlled experiment that provided supplementary insect food (nutritionally enhanced mealworms supplied daily to meet $40 \%-50 \%$ of each supplemented brood's food requirements) to great tit nestlings in urban and forest habitats.

3. We measured parental provisioning rates and estimated the amount of supplementary food consumed by control and experimental nestlings, and assessed their body size and survival rates.

4. Provisioning rates were similar across habitats and control and supplemented broods, but supplemented (and not control) broods consumed large quantities of supplementary food. As predicted by the food limitation hypothesis we found that nestlings in (a) urban control broods had smaller body size and nestling survival rates than those in forest control broods; (b) forest supplemented and control broods had similar body size and survival rates; (c) urban supplemented nestlings had larger body size and survival rates than those in urban control broods; and crucially (d) urban supplemented broods had similar body size and survival rates to nestlings in forest control broods.

5. Our results provide rare experimental support for the strong negative effects of food limitation during the nestling rearing period on urban birds' breeding success. Furthermore, the fact that supplementary food almost completely eliminated habitat differences in survival rate and nestling body size suggest that urban stressors other than food shortage contributed relatively little to the reduced avian breeding success. Finally, given the impacts of the amount of supplementary food that we provided and taking clutch size differences into account, our results suggest that urban insect populations in our study system would need to be increased by a factor of at least 2.5 for urban and forest great tits to have similar reproductive success.

\section{KEYWORDS}

arthropod, breeding success, food limitation hypothesis, mortality, nestling food, supplementary food, urban birds, urbanization 


\section{1 | INTRODUCTION}

Population growth and socio-demographic factors are rapidly increasing the number and spatial extent of urban settlements across the globe (United Nations, 2016). Urbanization rates and associated human population densities concentrate in regions with high species richness and biodiversity hotspots (Luck, 2007; Seto, Güneralp, \& Hutyra, 2012). As urban areas-especially their core regions-typically support fewer species and less diverse biotic communities than surrounding semi-natural or natural landscapes (Aronson et al., 2014; Batáry, Kurucz, Suarez-Rubio, \& Chamberlain, 2018), urbanization is increasingly contributing to the extinction crisis (Chaudhary, Pourfaraj, \& Mooers, 2018; Mcdonald, Kareiva, \& Forman, 2008). Improved understanding of the factors that limit urban biodiversity is needed to devise urban management strategies that can enhance species' occurrence and population sizes in towns and cities, thus contributing to local, and sometimes global, conservation objectives (Ives et al., 2016; Lepczyk et al., 2017).

Urban biodiversity is limited by numerous factors including the spatial extent, composition and structure of vegetation, exposure to a range of pollutants (e.g. chemical, noise, heat), human disturbance and reduced availability of high-quality resources including food (Aronson et al., 2017; Moretto \& Francis, 2017; Williams et al., 2009). Specifically, the food limitation hypothesis proposes that the reproductive performance of urban animals is limited by the reduced availability of high-quality food sources, for example insects. Although insects' responses to urbanization are diverse and taxon specific, several studies have found that urban areas generally support fewer insects than more natural habitats (Jones \& Leather, 2012; New, 2015). Indeed, cities typically have reduced abundance of lepidopteran larvae (reviewed by Seress et al., 2018), that are key and preferred components of offspring diet in many insectivorous species, including most passerines, in their natural breeding habitats (Cholewa \& Wesołowski, 2012).

In contrast to the relative scarcity of natural food items, urban environments typically contain large amounts of anthropogenic food which is readily consumed by a range of species and can comprise a substantial proportion of the animals' diets (e.g. arthropods Youngsteadt, Ernst, Dunn, \& Frank, 2016, birds Robb, McDonald, Chamberlain, \& Bearhop, 2008 and mammalian carnivores Bateman \& Fleming, 2012). These anthropogenic food sources, however, are typically of lower nutritional quality than natural dietary components, and their consumption is often associated with adverse impacts on animals' physiology (e.g. Schulte-Hostedde, Mazal, Jardine, \& Gagnon, 2018), behaviour and disease risk (e.g. Murray et al., 2015; Murray, Hill, Whyte, \& St Clair, 2016), and reproductive success (Mennechez \& Clergeau, 2006; Plummer, Bearhop, Leech, Chamberlain, \& Blount, 2018). In combination, the abundant anthropogenic food sources and the scarcity of urban insects may drastically alter the quantity and quality of food for urban insectivorous animals, suggesting limited availability of high-quality food during the brood-rearing period (Seress \& Liker, 2015). These impacts have been particularly well studied in birds and, as predicted by the food limitation hypothesis, may contribute to the general pattern of lower reproductive success (e.g. fewer and smaller offspring) in urban compared to non-urban avian populations (Chamberlain et al., 2009; Sepp, McGraw, Kaasik, \& Giraudeau, 2017). The extent to which these reductions in breeding success are ultimately driven by reduced abundance of natural dietary components in urban locations is, however, unclear.

Food supplementation experiments are widely used in avian ecological research, but studies manipulating nestling food quantity and/or quality in urban environments are rare and have produced inconsistent evidence for the link between food limitation and reduced breeding success. One experiment (Bańbura et al., 2011) on urban great tits Parus major reported positive effects of extra food on some traits (nestling body size and blood heterophil-to-lymphocyte ratio) but not on others (several other blood parameters)-although in this study the extent to which focal parents and their nestlings used the extra food is unclear. Other food supplementation experiments on urban birds have found negligible (Meyrier et al., 2017) or even negative (Demeyrier, Charmantier, Lambrechts, \& Grégoire, 2017) impacts on body size and/or nestling survival. We are aware of only two studies that compared the effects of food supplementation between urban and non-urban populations of the same species. Supplementary food had similar positive effects on house sparrows' Passer domesticus nestling survival and number of fledglings in suburban and rural gardens, suggesting that the suburban sparrows were not more food limited than the rural birds (Peach, Sheehan, \& Kirby, 2014). This study, however, did not control for the confounding effects of brood size, nestling age and the amount of supplementary food obtained by different broods. A study on American crows Corvus brachyrhynchos found larger body size in urban supplemented nests, while in rural areas supplementary food reduced body size, but the study was limited by extremely small sample sizes with a total of just seven supplemented nests (Heiss, Clark, \& Mcgowan, 2009). These studies, with the exception of Bańbura et al. (2011), also provided no information on the amount of natural food in the urban and rural study systems and thus the potential magnitude of food shortage experienced by the focal urban bird populations. There is thus a need for additional tests of the urban food limitation hypothesis that build upon earlier work by conducting food supplementation experiments across urban and rural populations using larger sample sizes, quantifying the use of supplementary food by target individuals, placing this in the context of the difference in natural food availability of urban and rural bird populations, and assessing the influence of a wider range of potentially confounding variables on metrics of avian reproductive success.

In a recent study, we showed that lower breeding success of urban great tits is primarily driven by increased nestling mortality, for which starvation was the most likely explanation (Seress et al., 2018). Here, we build upon this finding and experimentally test the food limitation hypothesis using a food supplementation experiment in urban and forest populations. We regularly provisioned extra insect food throughout the brood-rearing period to manipulate nestlings' diet, and compared parental provisioning behaviour, nestling body size and 
survival between supplemented (treatment) and non-supplemented (control) broods within and between habitat types. We predicted that (a) control broods in the urban habitat would have reduced provisioning rates, nestling body size and survival compared to control broods in forest, indicating that food availability during the nestling phase limits breeding success in urban but not in forested areas, and thus (b) control and supplementary fed broods in forested locations would exhibit negligible differences in provisioning rate, body size and nestling survival, while (c) urban supplemented broods would have significantly increased provisioning rates, nestling body size and survival compared to urban control broods. Finally, if food limitation is indeed a major factor limiting breeding success and nestling development in cities, we expect to find that (d) extra insect food would eliminate or considerably mitigate the differences in reproductive success between urban supplemented and forest control groups.

\section{2 | MATERIALS AND METHODS}

\section{1 | Data collection and experimental design}

We studied great tits breeding in nest boxes at an urban and a forest site in Hungary in 2017. The urban study site is located in the city of Veszprém $\left(47^{\circ} 05^{\prime} 17.29^{\prime \prime} \mathrm{N}, 17^{\circ} 54^{\prime} 29.66^{\prime \prime} \mathrm{E}\right)$, where the nest boxes were placed in four areas of public green space, including public parks, university campuses and a cemetery, that are surrounded by built-up areas and roads and experience frequent anthropogenic disturbance. These sites comprise one relatively large core site (23.3 ha) and three smaller sites (3.1, 7.3 and 4.4 ha) located approximately 60, 620 and $730 \mathrm{~m}$ from the core site. Breeding great tits (individually marked with rings) have been observed to move between these plots during our long-term study of the population. The general habitat characteristics and dominant tree species are similar between these plots (Appendix S1) thus birds breeding in each of these urban subsites are likely to experience very similar foraging opportunities. The forest study site, Vilma-puszta, is located c. $3 \mathrm{~km}$ from the edge of Veszprém in mature deciduous woodland characterized mainly by downy oak Quercus cerris and South European flowering ash Fraxinus ornus $\left(47^{\circ} 05^{\prime} 06.7^{\prime \prime} \mathrm{N}, 17^{\circ} 51^{\prime} 51.4^{\prime \prime} \mathrm{E}\right.$; the study plot covers c. $\left.48.1 \mathrm{ha}\right)$. This latter study location is a Natura 2000 site which is relatively free from human disturbance, for example it has no paved roads, has only one nearby farm and no logging activity. Ringing data indicate extremely limited dispersal between the urban and rural study sites (one recorded instance from over 1,100 retrapping or resighting observations of c. 4,100 individually marked birds between 2011 and 2019).

To test the food limitation hypothesis, we manipulated nestlings' diet in a field experiment, in which great tit broods were allocated to a food supplementation treatment (treatment group) or received no extra food (control group). We monitored nest boxes at least twice a week from 1 March to early June to record laying and hatching dates, and the number of eggs and nestlings in active great tits nests. At each study site, we randomly assigned the first brood of the season to the supplemented or control group, and then sequentially allocated each additional brood to the supplemented or control groups to ensure similar sample sizes in each group and to avoid the potential for treatment type to be confounded with date. The experiment only included first broods (note that at these study sites most fledglings are produced by first broods; Seress et al., 2018). During the incubation period, we equipped all nest boxes with a feeder box, which was a small $(125 \mathrm{ml})$ plastic container attached to the nest box a few centimetres below the entrance (Appendix S1: Figure S1). This proximity to the nest box helped focal birds to defend the supplementary food from non-target individuals, which was further facilitated by opaque feeder boxes to decrease the conspicuousness of mealworms to other birds (use of mealworms by non-target individuals was very rare, see Section 3). The bottom of the feeder boxes had small holes (1 $\mathrm{mm}$ diameter) that enabled rainwater drainage but did not allow supplementary food (mealworms) to escape. Control and supplemented nests were not clustered within separate parts of the study sites, and the mean distance $( \pm S E)$ between the nearest neighbouring control and supplemented broods were $98 \pm 12 \mathrm{~m}$ (range: $37-211 \mathrm{~m})$ in the urban site and $67 \pm 8 \mathrm{~m}(31-112 \mathrm{~m})$ in the forest site.

Treatment broods received supplementary food on a daily basis when nestlings were 3-15 days old (hatching day of the first egg = day 1). This ensured that food supplementation did not influence reproductive success by altering clutch sizes or the body condition of incubating females. We adjusted the amount of mealworms according to brood size and nestling age by providing $1.5 \mathrm{~g} / \mathrm{chick} / \mathrm{day}$ between 3 and 7 days of nestling age (i.e. for 5 days), and 3 g/chick/ day between 8 and 15 days of nestling age (i.e. for 8 days). Thus, a brood with 10 nestlings received daily c. 120 and 240 larvae in the early and late nestling rearing phases respectively. These quantities are estimated to cover $40 \%-50 \%$ of daily food requirements of great tit nestlings (Gibb \& Bets, 1964; Van Balen, 1973, our own unpublished data). Mealworms are widely used in avian food supplementation experiments (Bańbura et al., 2011; Demeyrier et al., 2017; Peach et al., 2014), and are suggested to be a good source of energy and digestible amino acids for birds (Finke, 2002). To increase the nutritional value of mealworms we transferred the larvae from their usual wheat bran substrate to an ad libitum invertebrate food substrate rich in protein and vitamins (www.bugs-world.com, product code: BW-TT), at least 2-3 days before being provided to birds (for similar approach see e.g. Kaiser, Sillett, \& Webster, 2014). Daily food supplementation occurred between 8:00 and 13:00 hr, and during these visits we also recorded the number of chicks (alive or dead) in the nest, which enabled us to calculate the required amount of supplementary food for each brood. To avoid inducing nest desertion, we never removed brooding parents during these checks-thus, if a parent remained on the nest during nest inspection we used the most recent data on brood size to calculate the required amount of supplementary food. Feeding boxes were cleaned daily and leftover food was weighed (to the nearest g). Control broods did not receive supplementary food but their nests were also checked daily and we spent a similar amount of time (c. 3-4 min) at the nest during each visit to ensure that control and supplemented broods received the same level of human disturbance. 
When nestlings reached 15 days of age (i.e. just before fledging) we ringed and weighed them $( \pm 0.1 \mathrm{~g})$ and also measured the length of the left tarsus ( $\pm 0.1 \mathrm{~mm}$ ) and right wing $( \pm 1 \mathrm{~mm}$; from the bend of the wing to the tip of the longest primary, following the 'flattened and straightened wing' method; Svensson, 1992). In the supplemented group a few hours had always passed between the most recent provision of supplementary food and the measurements ( $4.68 \pm 0.14 \mathrm{hr}$ ) in order to let the birds digest the supplementary food.

The experiment involved 52 broods initially, but due to complete breeding failure resulting from nest desertion during the incubation or early chick-rearing period (which is usually due to parental death; Santema \& Kempenaers, 2018), we excluded five nests ( $n=3$ urban control, $n=1$ urban supplemented, $n=1$ forest supplemented). Thus final sample sizes were as follows: urban control broods 10 , urban supplemented broods 14, forest control broods 12 and forest supplemented broods 11 (Appendix S1: Table S1).

Frass sampling of the dominant tree species at each site demonstrated that, as was the case in previous years, caterpillar abundance was higher in the forest compared to the urban site in 2017 (Appendix S1: Figure S2; Seress et al., 2018). Breeding success of urban and forest pairs that did not receive supplementary food was comparable to that reported between 2013 and 2016 from the same study sites (Seress et al., 2018; Appendix S1: Tables S1-S2). During the experiment there was, however, a brief unusual cold spell from 18 to 21 April 2017 with occasional snowfall and low ambient temperatures (Glądalski et al., 2018; Appendix S2). During this period most urban nests already contained recently hatched nestlings (Appendix S2) while forest clutches were still being incubated (reflecting the typical trend for earlier laying in urban sites, see Seress et al., 2018). This adverse weather might have disproportionately affected the early development of urban nestlings. However, the exposure to the cold spell did not have a significant interaction with the treatment in models of any of our response variables, and control urban nestlings that experienced the cold spell did not have smaller body mass than non-manipulated broods from the same urban site from other years with normal weather conditions (Appendix S2). Thus, we conclude that it is highly unlikely that the exposure of urban broods to the cold spell biased the effects of the supplementary food treatment.

\subsection{Behavioural data collection}

Small video cameras (HD Hero, GoPro) mounted in a nontransparent plastic box for camouflage (c. $15 \mathrm{~cm}$ from the feeder) were used to monitor use of the feeder and parental provisioning behaviour (Seress et al., 2017). Videos (60 min duration) were recorded when chicks were $3-5$ days old $(M \pm S E$, supplemented group: $4.1 \pm 0.3$ day; control group: $4.3 \pm 0.1$ day) and 9-11 days old (supplemented group: $9.9 \pm 0.1$ day; control group: $10.0 \pm 0.1$ day). Due to logistical constraints videos ( $n=67$ ) were obtained for 42 broods, of which 25 were recorded at both chick ages, and 17 broods were only recorded when chicks were 9-11 days old. Videos were only taken during favourable weather conditions (i.e. not during heavy rain or strong winds) during the morning or early afternoon (urban: 09:00-14:30 hr; forest: 10:00-15:30 hr).

From each video, we extracted data on food provisioning rates (calculated per nestling). For supplemented broods we also categorized food items into three food types: mealworm, non-supplementary food (mainly caterpillars and other arthropods) or unidentified food item (eight of the 1,526 feeding events). We recorded if birds (of any species) other than the focal brood's parents took supplementary food from the feeder (parents could be identified by unique colour ring combinations (66 of the 84 focal parents) or unique plumage marks (e.g. width of the breast stripe and overall coloration; the remaining 18 parents). We never captured and ringed adults or measured nestlings before video recording to avoid possible disturbances to birds' behaviour (Seress et al., 2017). Finally, we also recorded if parents consumed supplementary food themselves (through either direct capture of the feeding event on the video or by assuming self-consumption if a parent took supplementary food but did not deliver it to nestlings on its subsequent visit to the nest box).

\section{3 | Statistical analysis}

We conducted three analyses to further investigate how parents used the supplementary food. First, we tested if urban and forest supplemented birds utilized the same proportion of the supplementary food that was provided during the entire nestling period and compared habitats using a Mann-Whitney test (data distributions did not permit parametric tests). Second, we calculated the proportion of mealworm prey in the nestling diet to investigate how much urban and forest parents supplemented their nestlings' diet with mealworms. We fitted a linear mixed model (LME, package NLME) in which the response variable was the ratio of mealworms across all prey items (the number of mealworms divided by the number of all food items; $n=8$ unidentified food items were excluded), and predictors were habitat, time of the day (number of minutes from 6:00 a.m. until the start of the video recording), nestling age and brood size. Note that as videos were recorded during the same short nestling age periods (3-5 and 9-11 days post-hatch), we included nestling age as a binary variable with these two age categories. We included brood ID as random factor to control for the non-independence of two video recordings on the same broods. Third, we also calculated the proportion of mealworms consumed by parents, and compared this ratio between habitats. We built a generalized linear mixed-effects model with quasi-binomial error distribution (gImmPQL, package MASs), in which the response variable was the ratio of mealworms consumed by the parents (number of consumed mealworms divided by the number of all utilized mealworms), and predictors were habitat, time of the day, nestling age (two-level factor) and brood size; brood ID was a random factor. From this latter analysis we excluded one video recording (an urban brood) because the parents did not consume or provision any mealworms during the 60-min video, so we could not calculate this ratio (although field observation and the usually zero amount 
of leftover food in the feeder confirmed that these parents usually utilized the supplementary food).

To test our specific predictions for the effects of food supplementation treatment on reproductive success (outlined in the Introduction) we followed the approach suggested by Ruxton and Beauchamp (2008) and applied pre-planned pairwise comparisons between specific groups of habitat and treatment combinations of interest, as this method is a powerful approach for testing a priori hypotheses. We conducted the comparisons in two steps: first, we built separate linear models for nestling body size traits, survival rate and nestling provisioning rate, and used these models to identify significant confounding variables besides the effects of treatment and habitat. Second, following the specific guidance of Ruxton and Beauchamp (2008) we conducted all the pre-planned comparisons (regardless of the results of the first stage analysis) and calculated linear contrasts between specific groups of habitat and treatment combinations from linear models that also contained the confounding variables that had significant effects. These steps are described in detail below.

First, we fitted separate LME models for nestlings' body mass, tarsus length and wing length (all measured on day 15). In these three models, predictors were food supplementation treatment (supplemented or control), habitat, treatment $\times$ habitat interaction, brood size and time of day when modelling body mass. We used brood ID as a random factor in all these models. We also included date (number of days elapsed from the 1st of January until the measurement) in these models, but because forest great tits laid on average 7-8 days later than their urban conspecifics (Seress et al., 2018), we found a moderate level of collinearity between habitat type and date (variance inflation factor [VIF] > 3.26 in all cases, i.e. above the threshold at which collinearity is a concern (Zuur, leno, \& Elphick, 2010); using function 'vif' from package CAR). Thus, to reduce multicollinearity we mean-centered the date separately for urban and forest broods and used this transformed variable in the models.

The food limitation hypothesis predicts lower nestling survival due to starvation in urban areas. Thus, we calculated the proportion of nestlings surviving from day 3 to day 15 (i.e. from the start of the experiment until ringing) and built a GLM with binomial error distribution, logit link function. In this model, the response variable was the proportion of nestlings surviving (i.e. the unit of analysis was individual broods and thus we did not include brood identity as a random factor), and predictors were treatment, habitat, treatment $\times$ habitat interaction, mean-centred date and brood size. Because in the forest supplemented group survival rate was 1.00 (i.e. all nestlings survived), we applied Firth logistic regression (using package BRGLM) to handle the problem of separation.

We also analysed the provisioning rates of parents in an LME model in which the response variable was provisioning rate (transformed as $\left.\log _{e}(x+0.5)\right)$, and predictors were treatment, habitat, treatment $\times$ habitat, mean-centred date, time of the day and nestling age (two-level factor); random factor was brood ID. We were unable to include potential confounding effects of parental age, a possible proxy for experience, because this would have reduced sample sizes by between $11 \%$ and $30 \%$ for each comparison group-generating an unhelpful reduction in statistical power. Consideration of the age of parents for which data were available strongly suggests, however, that our results and inference are not biased by variation in parental age across our four groups of birds (urban control, urban supplemented, forest control and forest supplemented; Appendix S1: Table S3). We report the results for all full models in (Appendix S1: Table S4).

In the second step, we used separate linear models to compare the means of the response variables (i.e. the three nestling body size traits, survival rate and nestling provisioning rate) between specific habitat-treatment combinations. These models always contained the habitat $\times$ treatment term, plus any other confounding variable that was significant in the above described models (Appendix S1: Table S4), specifically: date in the tarsus length and survival rate models, and nestling age (as two-level factor) in the nestling provisioning rate model; the random factor was brood ID (except for the model on nestling survival). We calculated linear contrasts between groups and used function ' $g l$ ht' (in package MULTCOMP) to test whether these contrast differed from zero after applying the false discovery rate (FDR) method for correcting $p$-values for multiple pairwise comparisons. Specifically, we compared the means of the above five response variables between the following groups: (a) forest control versus urban control (to confirm the effect of habitat on control broods); (b) forest control versus forest supplemented and (c) urban control versus urban supplemented (to test for the effects of supplementary food within habitat types); and finally, (d) forest control versus urban supplemented (to test whether the food supplementation was sufficient to eliminate or considerably mitigate differences between habitats).

To aid the interpretation of nestling survival analyses, we calculated survival probabilities of nestlings in the four groups from the model's parameter estimates. We used the same GLM as in the linear contrast analysis (see above) and transformed the habitat-treatment group mean estimates ( $b$, provided on a logit scale) of the proportion of survived nestlings to survival probabilities $(p)$ using the formula: $p=\exp (b) /(1+\exp (b) ;$ Zuur, leno, Walker, Saveliev, \& Smith, 2009)-this is referred to as the survival probability in the rest of the manuscript.

All analyses were conducted in R (v. 3.5.2, R Core Team). We checked the validity of statistical assumptions for each linear model described above (Zuur et al., 2009), and the calculated VIF values for all our models (VIF < 2.55) were below the threshold at which results are influenced by collinearity (Zuur et al., 2010). We define the twotailed statistical significance level at $p<0.05$.

\section{3 | RESULTS}

\subsection{Acceptance of supplementary food and provisioning behaviour of the parents}

Videos showed that birds in both habitats used most of the supplementary food, and we found no significant difference in the ratio of the amount of leftover food between urban (1.4\%) and forest (4.2\%) supplemented nests (Mann-Whitney, $n=25, W=66, p=0.542$ ). 
Videos also revealed that birds other than the nest owners occasionally visited the nest boxes both in the control and in the supplemented groups. Species that visited the nest boxes (in control and supplemented groups combined) included great tits (seven cases), great spotted woodpeckers Dendrocopos major (three cases), collared flycatchers Ficedula albicollis (two cases), tree sparrows Passer montanus (two cases) and a blue tit Cyanestes caeruleus. Visitor birds appeared on $16.7 \%$ (five out of the 30 ) of the control videos, and on $24.3 \%$ (nine out of 37) of the supplemented videos, stealing mealworms from the feeders in six out of the nine videos. However, on these six videos (five urban and one forest), the amount of food stolen ( 57 mealworms in total, $M \pm S E: 8.14 \pm 3.12$ per video) was small compared to the amounts utilized by the focal parents (390 mealworms, $55.71 \pm 11.14$; paired $t$ test, $t_{6}=3.72, p=0.009$ ). Visiting great tits (all in the urban habitat) may have largely comprised of floaters and were either not ringed, or were ringed but not included in the experiment, except one urban male that was the parent of a neighbouring supplemented brood. We did not record any great tits from the control group stealing supplementary food from the feeders on supplemented nest boxes.
In supplemented nests we found that parents readily fed their chicks with the supplementary food, as the proportion of mealworms in nestlings' diet was $81.1 \%$ in urban and $75.3 \%$ in forest broods, but neither habitat type (LME, $b \pm S E: 0.02 \pm 0.09, t_{21}=0.192, p=0.849$ ), nor any other predictor had significant influence on the proportion of mealworm in the diet of supplemented nestlings ( $p>0.351$ in all cases). Investigating the proportion of mealworms that parents consumed, we found a marginally non-significant habitat effect (GLM, $b \pm S E: 0.55 \pm 0.31, t_{20}=1.77, p=0.093$ ), with urban parents tending to consume more mealworms (24.7\%) than forest parents (18.1\%). We also found a significant effect of nestling age, as parents consumed more extra food themselves when they were raising younger nestlings (3-5 days old) compared to when they were provisioning older chicks (9-11 days; GLM, $b \pm S E$ : $-0.80 \pm 0.28, t_{13}=-2.83, p=0.014$ ).

Nestling provisioning rate was similar between treatment groups and habitats, and none of the four pre-planned pairwise comparisons revealed significant differences between groups (Table 1a). Provisioning rate was significantly higher in the 9- to 11-day compared to the 3- to 5-day old age category (Appendix S1: Table S4).

\begin{tabular}{|c|c|c|c|}
\hline Pairwise comparisons & Contrast $\pm S E$ & $z$ & Adj. $p$ \\
\hline \multicolumn{4}{|l|}{ (a) Provisioning rate (feeding/nestling $/ \mathrm{hr})^{\mathrm{a}}$} \\
\hline Forest control-urban control & $0.20 \pm 0.21$ & 0.94 & 0.654 \\
\hline Forest control-forest supplemented & $-0.09 \pm 0.20$ & -0.45 & 0.654 \\
\hline Urban control-urban supplemented & $-0.31 \pm 0.20$ & -1.53 & 0.502 \\
\hline Forest control-urban supplemented & $-0.12 \pm 0.17$ & -0.66 & 0.654 \\
\hline \multicolumn{4}{|l|}{ (b) Nestling body mass (g; day 15$)^{b}$} \\
\hline Forest control-urban control & $2.90 \pm 0.52$ & 5.54 & $<0.001$ \\
\hline Forest control-forest supplemented & $-0.78 \pm 0.48$ & -1.61 & 0.107 \\
\hline Urban control-urban supplemented & $-2.00 \pm 0.51$ & -3.92 & $<0.001$ \\
\hline Forest control-urban supplemented & $0.90 \pm 0.46$ & 1.97 & 0.066 \\
\hline \multicolumn{4}{|l|}{ (c) Nestling wing length (mm; day 15$)^{\mathrm{b}}$} \\
\hline Forest control-urban control & $9.13 \pm 1.79$ & 5.10 & $<0.001$ \\
\hline Forest control-forest supplemented & $-0.73 \pm 1.66$ & -0.44 & 0.662 \\
\hline Urban control-urban supplemented & $-5.55 \pm 1.74$ & -3.19 & 0.003 \\
\hline Forest control-urban supplemented & $3.58 \pm 1.58$ & 2.27 & 0.031 \\
\hline \multicolumn{4}{|l|}{ (d) Nestling tarsus length (mm; day 15$)^{b}$} \\
\hline Forest control-urban control & $1.25 \pm 0.35$ & 3.59 & 0.001 \\
\hline Forest control-forest supplemented & $-0.34 \pm 0.31$ & -1.12 & 0.348 \\
\hline Urban control-urban supplemented & $-1.06 \pm 0.34$ & -3.09 & 0.004 \\
\hline Forest control-urban supplemented & $0.19 \pm 0.29$ & 0.66 & 0.512 \\
\hline \multicolumn{4}{|c|}{ (e) Nestling survival (between days 3 and 15$)^{c}$} \\
\hline Forest control-urban control & $2.67 \pm 0.50$ & 5.33 & $<0.001$ \\
\hline Forest control-forest supplemented & $-2.48 \pm 1.49$ & -1.67 & 0.096 \\
\hline Urban control-urban supplemented & $-1.68 \pm 0.37$ & -4.49 & $<0.001$ \\
\hline Forest control-urban supplemented & $0.99 \pm 0.53$ & 1.86 & 0.084 \\
\hline
\end{tabular}

TABLE 1 The results of the preplanned pairwise comparisons showing the differences in (a) great tit parents' provisioning rates (log-transformed using the formula $\log _{e}(x+0.5)$ and in their nestlings' $(b-d)$ body size and (e) proportion of survived nestlings (on a logit scale) between groups of treatment $\times$ habitat combinations. The linear contrasts between groups were calculated from linear models (LME for a-d and GLM for e), containing the habitat $\times$ treatment interaction, plus any confounding variable that was proven to be significant in the full model (Appendix S1: Table S4). Statistically significant $(p<0.05)$ differences are highlighted in bold and marginally non-significant $(0.05<p<0.10)$ differences are shown in italic

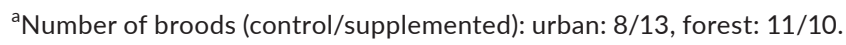

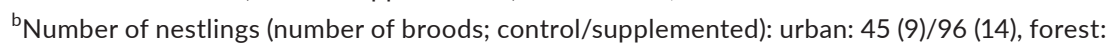
99 (12)/104 (11).

'Number of broods (control/supplemented): urban: 10/14, forest: 12/11. 
FIGURE 1 Differences $(M \pm S E)$ in 15 days old great tit nestlings' (a) body mass, (b) wing length, (c) tarsus length and (d) nestling survival in the groups of different habitat $\times$ treatment combinations
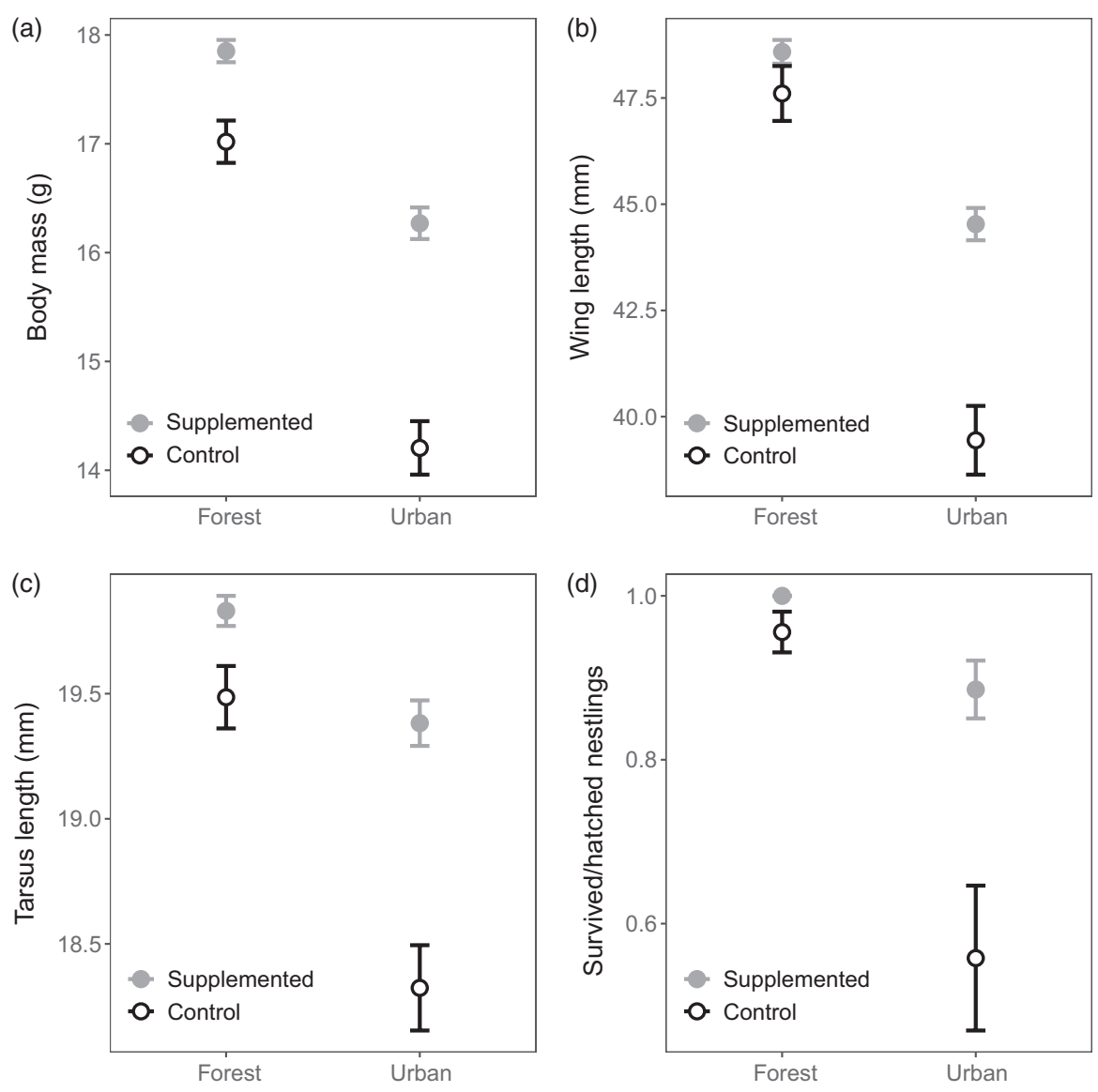

\subsection{Nestling body size}

The results of the pre-planned pairwise comparisons for body mass, wing and tarsus lengths confirmed that (a) forest control nestlings were significantly larger than urban control nestlings for all three body size metrics (Figure 1a-c; Table 1b-d). In line with our expectations, we found that (b) forest control and forest supplemented groups did not differ significantly in any variables, whereas (c) supplementary feeding significantly increased body mass, wing and tarsus lengths in urban supplemented nestlings compared to the control group (Figure 1a-c; Table 1b-d). Finally, (d) supplementary feeding effectively mitigated the differences in body mass, wing and tarsus lengths that occurred between control forest and urban broods (Figure 1a-c; Table 1b-d). Although the difference between forest control and urban supplemented groups was close to statistical significance in body mass (Table $1 \mathrm{~b}$ ) and was statistically significant in wing length (Table 1c), the magnitude of these differences were small (body mass $[\mathrm{g}]$ : $0.90 \pm 0.46$, wing length [mm]: $3.58 \pm 1.58$ ).

\section{3 | Nestling survival}

Nestling survival probabilities ( $p$ ), estimated from the GLM model, were 1.00 and 0.95 in forest supplemented and control broods, respectively, while this was 0.88 in the urban supplemented and only 0.58 in urban control broods. The pre-planned pairwise comparisons indicated significant differences in nestling survival probabilities between (a) forest control and urban control groups (Table 1e; Figure 1d). The difference in survival probability between (b) forest supplemented and forest control groups was close to statistical significance but remained slight, whereas (c) survival was significantly and considerably higher in the urban supplemented compared to the urban control groups (Table 1e; Figure 1d). Finally, while we found that the difference in survival probability (d) between the forest control and urban supplemented groups was close to statistical difference its magnitude was small; Table 1e; Figure 1d).

\section{4 | DISCUSSION}

Urbanization can be associated with adverse impacts on demographic traits (Sepp et al., 2017), and these impacts probably contribute to the reduced biodiversity of towns and cities (Aronson et al., 2014). The mechanisms driving reduced demographic success in urban environments are, however, poorly understood (Rodewald $\&$ Gehrt, 2014). In this study we used a food supplementation experiment, using mealworms fed on an enriched diet, to test if the reduced abundance of insect food sources in urban environments (e.g. Seress et al., 2018) explains reduced reproductive success and smaller nestling size in an insectivorous bird.

As predicted by the food limitation hypothesis, control broods that did not receive supplementary food were smaller and had lower 
survival rates in the urban site than the forest site-matching previous studies of reproductive success in unmanipulated great tit populations (Bailly et al., 2016; de Satgé et al., 2019) including our focal study populations (Seress et al., 2018). Crucially, urban supplemented broods had considerably higher fledging success and produced larger nestlings than urban control pairs, whereas supplementary feeding of forest broods had only small and statistically non-significant effects on these traits. Furthermore, supplementary-fed urban broods had similar body sizes and survival rates to those of control broods in the forest environment. Collectively, these results provide rare and strong experimental evidence that the negative impacts of urbanization on avian nestling size and survival are caused by the reduced availability of high-quality invertebrate food sources, and these effects can be mitigated by providing arthropod-based supplementary food. Our experiment suggests that food limitation can strongly influence even successful urban adapter species such as the great tit, which across its range is one of the commonest birds in towns and cities (Gosler \& Clement, 2007). The very small differences in nestling size and survival between urban supplemented and forest control chicks suggest that food availability alone can explain much of the reduction in reproductive success in insectivorous woodland bird species occupying temperate urban environments. Other urban stressors, such as habitat modification and light pollution, thus seem likely to play only a limited direct role in lowering the productivity of insectivorous passerines in these situations-although their indirect effects on birds via reducing urban populations of moths and other insects might be still substantial.

The positive effects of supplementary food on urban nestlings' body size and survival were clearly detectable and strong compared to previous studies in urban great tit populations (Bańbura et al., 2011; Demeyrier et al., 2017). Although these earlier studies differ in several methodological details from our experiment (measured traits, length of food supplementation, type of food, etc.) the much stronger effect we found may arise primarily due to the enhanced quality of mealworms and the higher amounts of extra food per nestling we provided throughout most of the brood-rearing period. Alternatively or additionally, the natural availability of arthropods may be lower in our urban site than in the habitats involved in the above studies, making supplementary food more valuable and effective in our experiment (Ruffino, Salo, Koivisto, Banks, \& Korpimäki, 2014). The estimated biomass of arboreal caterpillars (the optimal nestling food for many passerines; Cholewa \& Wesołowski, 2012) during the brood-rearing period in our urban site was extremely low (approximately eight times higher in the forest site; and similar even more dramatic differences in caterpillar biomass occur in other years, 2013-2016, Appendix S1: Figure S2; Seress et al., 2018), but we consider such differences to be a common feature of urban environments (Hajdasz, Otter, Baldwin, \& Reudink, 2019; Marciniak, Nadolski, Nowakowska, Loga, \& Bańbura, 2007; Pollock, CapillaLasheras, McGill, Helm, \& Dominoni, 2017; Shawkey, Bowman, \& Woolfenden, 2004).

The strong treatment effect that we found on urban but not on forest birds' breeding success is unlikely to be driven by the more extensive use of supplementary food by urban parents than those in the forest habitat for three reasons. First, the amounts of leftover food was very low in both habitats, and consecutive nest checks on day 15 (i.e. food supplementation and later that day, nestling measurements) also indicated that birds usually consumed all the provided food within a few hours. Second, the video recordings confirmed that the supplemented mealworms were utilized predominantly by supplemented parents in both habitats. Finally, the videos confirmed that the proportion of mealworms in the nestling diet was high in both urban (81\%) and forest (75\%) supplemented broods. It thus appears clear that forest birds are not food limited, and importantly that supplementary feeding with nutritionally enhanced mealworms provided forest supplemented pairs with a food source that was of broadly similar nutritional quality to the food sources utilized by forest control pairsotherwise one would expect supplemented pairs to have lower nestling body size and survival rates than the controls.

Besides the presumable direct (calorific and nutritional) benefits of the extra arthropod food on urban broods, indirect mechanisms might also have played a role in improving brood performance. The parents of supplemented broods consumed significant proportions of the mealworms themselves, and this tended to be higher in urban pairs. The resultant reduction in the time parents needed to invest in foraging for themselves, and the potentially higher body condition, may have enabled females to invest more in brooding and feeding young nestlings. Additionally, food supplementation can also enhance breeding success by increasing parents' nest defence behaviour, for example because parents can spend more time in the proximity of their nest and thus defend it against predators (see Vafidis, Facey, Leech, \& Thomas, 2018 and references). We did not record brood losses attributable to nest predation in any of our experimental groups, thus it is unlikely that this latter mechanism played an important role in our case-although it may be important in other regions or species with higher rates of nest predation.

Finally, our data can provide a broad indication of the magnitude of urban food limitation in this study system. Supplying $40 \%-50 \%$ of urban nestlings food requirements enabled them to more or less match the performance of forest broods. This implies that, at current densities and brood sizes, urban caterpillar populations need to be doubled if urban and rural chicks are to have similar performance without supplementary food. Urban great tit brood sizes are, however, typically c. $75 \%$ of those of forest broods in our study areas (Seress et al., 2018). Assuming that such reductions are driven by food limitation and that clutch size linearly increases with food availability it seems likely that urban caterpillar populations need to be increased by at least a factor of 2.5 to equalize urban and forest great tit brood size and performance. However, much higher increases are likely to be required given that other urban passerine species, including other tit species or woodpeckers (Smith \& Smith, 2019), also depend on caterpillars for provisioning their young and will thus compete to some extent with great tits. Achieving such large increases will be challenging-although there is substantial capacity to increase the volume 
of urban tree canopy through tree planting (Kroeger, McDonald, Boucher, Zhang, \& Wang, 2018), the benefits of this would take time to accumulate and many urban trees fail to come close to their mature size due to high mortality rates (Widney, Fischer, \& Vogt, 2016).

This study provides rare experimental evidence for the strong effects of food limitation in urban areas on avian nestling size and survival rates. Provision of mealworms that are fed on an enriched diet largely mitigated the marked differences in nestling size and survival rates between non-supplemented urban and forest broods. Our focal species specializes on provisioning nestlings with caterpillars, which is a common strategy in many groups of birds occurring in urban areas across the temperate zone including tits, chickadees, finches and woodpeckers. Thus, food limitation may be a similarly major factor limiting reproductive success in several other urbanized bird species. The provision of higher quality supplementary food to such species during the breeding season may increase the body size and nestling survival rates in their urban populations. The increased growth might have also yielded additional fitness advantages for urban supplemented broods given that effects of early nutritional conditions can be carried to adulthood, affecting adult body size (e.g. Cleasby, Burke, Schroeder, \& Nakagawa, 2011) or even cognitive abilities such as song learning (Nowicki, Searcy, \& Peters, 2002). Urban nestlings' benefit from the arthropod-rich food was especially prominent in their pre-fledging body mass (ca. $2 \mathrm{~g}$ ), which might have also increased their recruitment rate (Schwagmeyer \& Mock, 2008) given that pre-fledging body mass correlates positively with post-fledging survival in many passerine species, including great tits (Magrath, 1991). To what extent could the increased nestling survival and development contribute to urban populations' size and stability is still an unanswered question though. For example, while supplementary feeding improved breeding success in suburban house sparrows (Peach et al., 2014) this did not generate an increase in population size (Peach, Mallord, Ockendon, Orsman, \& Haines, 2018). While further work on the impacts of supplementary feeding on population dynamics is certainly needed, it is clear that the decreased abundance of key arthropod food sources in urban areas can limit avian reproductive success. Thus, management methods that overcome this limitation are likely to be beneficial in supporting and enhancing urban biodiversity, especially considering the marked and ongoing decline of global insect populations (see Owens et al., 2019 and references in it).

\section{ACKNOWLEDGEMENTS}

This research was supported by a grant from the National Research, Development and Innovation Office (NKFIH) of Hungary (K112838) and by the 1783-3/2018/FEKUSTRAT grant of the Hungarian Ministry of Human Capacities. G. Seress was supported by an NKFIH postdoctoral grant (PD 120998). We are also thankful to F. Seelje and F. Versloot (undergraduate students of the University of Groningen) for their immense help during the fieldwork, to V. Bókony for her advices in the statistical analyses and the two anonymous referees for their comments on the earlier version of the manuscript. The study was licensed by the Middle Transdanubian Inspectorate for Environmental Protection, Natural Protection and Water Management (permission numbers: 24861/2014).

\section{AUTHORS' CONTRIBUTIONS}

G.S. and A.L. conceived the ideas; G.S. and K.S. designed the methodology, collected and prepared the data; G.S. analysed the data with advice from K.L.E.; G.S., K.L.E. and A.L. interpreted the data and wrote the manuscript; and all the authors worked on the manuscript's revision and gave final approval for publication.

\section{DATA AVAILABILITY STATEMENT}

Data available from the Dryad Digital Repository: https://doi. org/10.5061/dryad.qbzkh18dj (Seress, Sándor, Evans, \& Liker, 2020).

\section{ORCID}

Gábor Seress iD https://orcid.org/0000-0001-9828-4934

Krisztina Sándor (iD https://orcid.org/0000-0003-4013-7418

Karl L. Evans (D) https://orcid.org/0000-0002-3492-8072

András Liker (iD https://orcid.org/0000-0001-8545-4869

\section{REFERENCES}

Aronson, M. F. J., La Sorte, F. A., Nilon, C. H., Katti, M., Goddard, M. A., Lepczyk, C. A., ... Winter, M. (2014). A global analysis of the impacts of urbanization on bird and plant diversity reveals key anthropogenic drivers. Proceedings of the Royal Society B: Biological Sciences, 281, 20133330. https://doi.org/10.1098/rspb.2013.3330

Aronson, M. F. J., Lepczyk, C. A., Evans, K. L., Goddard, M. A., Lerman, S. B., Maclvor, J. S., ... Vargo, T. (2017). Biodiversity in the city: Key challenges for urban green space management. Frontiers in Ecology and the Environment, 15, 189-196. https://doi.org/10.1002/fee.1480

Bailly, J., Scheifler, R., Berthe, S., Clément-Demange, V.-A., Leblond, M., Pasteur, B., \& Faivre, B. (2016). From eggs to fledging: Negative impact of urban habitat on reproduction in two tit species. Journal of Ornithology, 157, 377-392. https://doi.org/10.1007/s10336-0151293-3

Bańbura, J., Bańbura, M., Glądalski, M., Kaliński, A., Markowski, M., Michalski, M., ... Zieliński, P. (2011). Body condition parameters of nestling Great tits Parus major in relation to experimental food supplementation. Acta Ornithologica, 46, 207-212.

Batáry, P., Kurucz, K., Suarez-Rubio, M., \& Chamberlain, D. E. (2018). Non-linearities in bird responses across urbanization gradients: $A$ meta-analysis. Global Change Biology, 24, 1046-1054. https://doi. org/10.1111/gcb.13964

Bateman, P. W., \& Fleming, P. A. (2012). Big city life: Carnivores in urban environments. Journal of Zoology, 287(1), 1-23. https://doi. org/10.1111/j.1469-7998.2011.00887.x

Chamberlain, D. E., Cannon, A. R., Toms, M. P., Leech, D. I., Hatchwell, B. J., \& Gaston, K. J. (2009). Avian productivity in urban landscapes: A review and meta-analysis. Ibis, 151, 1-18. https://doi.org/ 10.1111/j.1474-919X.2008.00899.x

Chaudhary, A., Pourfaraj, V., \& Mooers, A. O. (2018). Projecting global land use-driven evolutionary history loss. Diversity and Distributions, 24, 158-167. https://doi.org/10.1111/ddi.12677

Cholewa, M., \& Wesołowski, T. (2012). Nestling food of European hole-nesting passerines: Do we know enough to test the adaptive hypotheses on breeding seasons? Acta Ornithologica, 46, 105-116. https://doi.org/10.3161/000164511X625874 
Cleasby, I. R., Burke, T., Schroeder, J., \& Nakagawa, S. (2011). Food supplements increase adult tarsus length, but not growth rate, in an island population of house sparrows (Passer domesticus). BMC Research Notes, 4, 431. https://doi.org/10.1186/1756-0500-4-431

de Satgé, J., Strubbe, D., Elst, J., De Laet, J., Adriaensen, F., \& Matthysen, E. (2019). Urbanisation lowers great tit Parus major breeding success at multiple spatial scales. Journal of Avian Biology, 50. https://doi. org/10.1111/jav.02108

Demeyrier, V., Charmantier, A., Lambrechts, M. M., \& Grégoire, A. (2017). Disentangling drivers of reproductive performance in urban great tits: A food supplementation experiment. The Journal of Experimental Biology, 220(22), 4195-4203. https://doi.org/10.1242/jeb.161067

Finke, M. D. (2002). Complete nutrient composition of commercially raised invertebrates used as food for insectivores. Zoo Biology, 21, 269-285. https://doi.org/10.1002/zoo.10031

Gibb, J. A., \& Bets, M. M. (1964). Food and food supply of nestling tits (paridae) in Beckland pine. Journal of Animal Ecology, 32, 489-533.

Glądalski, M., Bańbura, M., Kaliński, A., Markowski, M., Skwarska, J., Wawrzyniak, J., ... Bańbura, J. (2018). Hatching delays in great tits and blue tits in response to an extreme cold spell: A long-term study. International Journal of Biometeorology, 62, 1437-1445. https://doi. org/10.1007/s00484-018-1541-3

Gosler, A. G., \& Clement, P. (2007). Great tit (Parus major). In J. del Hoyo, A. Elliott, \& D. A. Christie (Eds.), Handbook of the birds of the world (Vol. 12, pp. 662-750). Picathartes to tits and chickadees. Barcelona, Spain: Lynx Edicions.

Hajdasz, A. C., Otter, K. A., Baldwin, L. K., \& Reudink, M. W. (2019). Caterpillar phenology predicts differences in timing of mountain chickadee breeding in urban and rural habitats. Urban Ecosystems, 22, 1113-1122. https://doi.org/10.1007/s11252-019-00884-4

Heiss, R. S., Clark, A. B., \& Mcgowan, K. J. (2009). Growth and nutritional state of American crow nestlings vary between urban and rural habitats. Ecological Applications, 19, 829-839. https://doi.org/ 10.1890/08-0140.1

Ives, C. D., Lentini, P. E., Threlfall, C. G., Ikin, K., Shanahan, D. F., Garrard, G. E., ... Kendal, D. (2016). Cities are hotspots for threatened species. Global Ecology and Biogeography, 25, 117-126. https://doi.org/ 10.1111/geb.12404

Jones, E. L., \& Leather, S. R. (2012). Invertebrates in urban areas: A review. European Journal of Entomology, 109, 463-478. https://doi. org/10.14411/eje.2012.060

Kaiser, S. A., Sillett, T. S., \& Webster, M. S. (2014). Phenotypic plasticity in hormonal and behavioural responses to changes in resource conditions in a migratory songbird. Animal Behaviour, 96, 19-29. https:// doi.org/10.1016/j.anbehav.2014.07.004

Kroeger, T., McDonald, R. I., Boucher, T., Zhang, P., \& Wang, L. (2018). Where the people are: Current trends and future potential targeted investments in urban trees for PM10 and temperature mitigation in 27 U.S. Cities. Landscape and Urban Planning, 177, 227-240. https:// doi.org/10.1016/j.landurbplan.2018.05.014

Lepczyk, C. A., Aronson, M. F. J., Evans, K. L., Goddard, M. A., Lerman, S. B., \& Maclvor, J. S. (2017). Biodiversity in the city: Fundamental questions for understanding the ecology of urban green spaces for biodiversity conservation. BioScience, 67, 799-807. https://doi. org/10.1093/biosci/bix079

Luck, G. W. (2007). A review of the relationships between human population density and biodiversity. Biological Reviews, 82, 607-645. https://doi.org/10.1111/j.1469-185X.2007.00028.x

Magrath, R. D. (1991). Nestling weight and juvenile survival in the blackbird, Turdus merula. The Journal of Animal Ecology, 60, 335-351. https://doi.org/10.2307/5464

Marciniak, B., Nadolski, J., Nowakowska, M., Loga, B., \& Bańbura, J. (2007). Habitat and annual variation in arthropod abundance affects Blue tit Cyanistes caeruleus reproduction. Acta Ornithologica, 42, 53-62.
Mcdonald, R. I., Kareiva, P., \& Forman, R. T. T. (2008). The implications of current and future urbanization for global protected areas and biodiversity conservation. Biological Conservation, 141, 1695-1703. https://doi.org/10.1016/j.biocon.2008.04.025

Mennechez, G., \& Clergeau, P. (2006). Effect of urbanisation on habitat generalists: Starlings not so flexible? Acta Oecologica, 30, 182-191. https://doi.org/10.1016/j.actao.2006.03.002

Meyrier, E., Jenni, L., Bötsch, Y., Strebel, S., Erne, B., \& Tablado, Z. (2017). Happy to breed in the city? Urban food resources limit reproductive output in western jackdaws. Ecology and Evolution, 7, 1363-1374. https://doi.org/10.1002/ece3.2733

Moretto, L., \& Francis, C. M. (2017). What factors limit bat abundance and diversity in temperate, North American urban environments? Journal of Urban Ecology, 3, jux016.

Murray, M. H., Cembrowski, A., Latham, A. D. M., Lukasik, V. M., Pruss, S., \& St Clair, C. C. (2015). Greater consumption of protein-poor anthropogenic food by urban relative to rural coyotes increases diet breadth and potential for human-wildlife conflict. Ecography, 38, 1235-1242. https://doi.org/10.1111/ecog.01128

Murray, M. H., Hill, J., Whyte, P., \& St Clair, C. C. (2016). Urban compost attracts coyotes, contains toxins, and may promote disease in urban-adapted wildlife. EcoHealth, 13, 285-292. https://doi.org/ 10.1007/s10393-016-1105-0

New, T. R. (Ed.). (2015). Insect conservation and urban environments (1st ed.). Cham, Switzerland: Springer International Publishing. https:// doi.org/10.1007/978-3-319-21224-1

Nowicki, S., Searcy, W. A., \& Peters, S. (2002). Brain development, song learning and mate choice in birds: A review and experimental test of the "nutritional stress hypothesis". Journal of Comparative Physiology A: Sensory, Neural, and Behavioral Physiology, 188, 1003-1014. https:// doi.org/10.1007/s00359-002-0361-3

Owens, A. C. S., Cochard, P., Durrant, J., Farnworth, B., Perkin, E. K., \& Seymoure, B. (2019). Light pollution is a driver of insect declines. Biological Conservation, 241, 108259.

Peach, W. J., Mallord, J. W., Ockendon, N., Orsman, C. J., \& Haines, W. G. (2018). Depleted suburban house sparrow Passer domesticus population not limited by food availability. Urban Ecosystems, 21, 1053-1065. https://doi.org/10.1007/s11252-018-0784-4

Peach, W. J., Sheehan, D. K., \& Kirby, W. B. (2014). Supplementary feeding of mealworms enhances reproductive success in garden nesting House Sparrows Passer domesticus. Bird Study, 61, 378-385.

Plummer, K. E., Bearhop, S., Leech, D. I., Chamberlain, D. E., \& Blount, J. D. (2018). Effects of winter food provisioning on the phenotypes of breeding blue tits. Ecology and Evolution, 8, 5059-5068. https://doi. org/10.1002/ece3.4048

Pollock, C. J., Capilla-Lasheras, P., McGill, R. A. R., Helm, B., \& Dominoni, D. M. (2017). Integrated behavioural and stable isotope data reveal altered diet linked to low breeding success in urban-dwelling blue tits (Cyanistes caeruleus). Scientific Reports, 7, 5014. https://doi.org/ 10.1038/s41598-017-04575-y

Robb, G. N., McDonald, R. A., Chamberlain, D. E., \& Bearhop, S. (2008). Food for thought: Supplementary feeding as a driver of ecological change in avian populations. Frontiers in Ecology and the Environment, 6, 476-484. https://doi.org/10.1890/060152

Rodewald, A. D., \& Gehrt, S. D. (2014). Wildlife population dynamics in urban landscapes. Urban wildlife conservation (pp. 117-147). Boston, MA: Springer. https://doi.org/10.1007/978-1-4899-7500-3_8

Ruffino, L., Salo, P., Koivisto, E., Banks, P. B., \& Korpimäki, E. (2014). Reproductive responses of birds to experimental food supplementation: A meta-analysis. Frontiers in Zoology, 11, 80. https://doi.org/ 10.1186/s12983-014-0080-y

Ruxton, G. D., \& Beauchamp, G. (2008). Time for some a priori thinking about post hoc testing. Behavioral Ecology, 19, 690-693. https://doi. org/10.1093/beheco/arn020 
Santema, P., \& Kempenaers, B. (2018). Complete brood failure in an altricial bird is almost always associated with the sudden and permanent disappearance of a parent. Journal of Animal Ecology, 87, 1239-1250. https://doi.org/10.1111/1365-2656.12848

Schulte-Hostedde, A. I., Mazal, Z., Jardine, C. M., \& Gagnon, J. (2018). Enhanced access to anthropogenic food waste is related to hyperglycemia in raccoons (Procyon lotor). Conservation Physiology, 6. https:// doi.org/10.1093/conphys/coy026

Schwagmeyer, P. L., \& Mock, D. W. (2008). Parental provisioning and offspring fitness: Size matters. Animal Behaviour, 75, 291-298. https:// doi.org/10.1016/j.anbehav.2007.05.023

Sepp, T., McGraw, K. J., Kaasik, A., \& Giraudeau, M. (2017). A review of urban impacts on avian life-history evolution: Does city living lead to slower pace of life? Global Change Biology, 24, 1-18. https://doi. org/10.1111/gcb.13969

Seress, G., Hammer, T., Bókony, V., Vincze, E., Preiszner, B., Pipoly, I., ... Liker, A. (2018). Impact of urbanization on abundance and phenology of caterpillars and consequences for breeding in an insectivorous bird. Ecological Applications, 28. 1143-1156. https://doi. org/10.1002/eap.1730

Seress, G., \& Liker, A. (2015). Habitat urbanization and its effects on birds. Acta Zoologica Academiae Scientiarum Hungaricae, 61, 373-408. https://doi.org/10.17109/AZH.61.4.373.2015

Seress, G., Sándor, K., Evans, K. L., \& Liker, A. (2020). Data from: Food availability limits avian reproduction in the city: An experimental study on great tits Parus major. Dryad Digital Repository, https://doi. org/10.5061/dryad.qbzkh18dj

Seress, G., Vincze, E., Pipoly, I., Hammer, T., Papp, S., Preiszner, B., ... Liker, A. (2017). Effects of capture and video-recording on the behavior and breeding success of Great Tits in urban and forest habitats. Journal of Field Ornithology, 88, 299-312. https://doi.org/10.1111/ jofo.12205

Seto, K. C., Güneralp, B., \& Hutyra, L. R. (2012). Global forecasts of urban expansion to 2030 and direct impacts on biodiversity and carbon pools. Proceedings of the National Academy of Sciences of the United States of America, 109, 16083-16088. https://doi.org/10.1073/pnas. 1211658109

Shawkey, M. D., Bowman, R., \& Woolfenden, G. E. (2004). Why is brood reduction in Florida scrub-jays higher in suburban than in wildland habitats? Canadian Journal of Zoology, 82, 1427-1435. https://doi. org/10.1139/z04-123

Smith, K. W., \& Smith, L. (2019). Does the abundance and timing of defoliating caterpillars influence the nest survival and productivity of the Great Spotted Woodpecker Dendrocopos major? Bird Study, 66, 187-197.

Svensson, L. (1992). Identification guide to European passerines (4th ed.). Thetford, UK: British Trust for Ornithology.

United Nations. (2016). UN-Habitat: World Cities Report 2016.

Vafidis, J. O., Facey, R. J., Leech, D., \& Thomas, R. J. (2018). Supplemental food alters nest defence and incubation behaviour of an open-nesting wetland songbird. Journal of Avian Biology, 49, e01672. https://doi. org/10.1111/jav.01672

Van Balen, J. H. (1973). A comparative sudy of the breeding ecology of the Great Tit Parus major in different habitats. Ardea, 61, 1-93.

Widney, S., Fischer, B. C., \& Vogt, J. (2016). Tree mortality undercuts ability of tree-planting programs to provide benefits: Results of a threecity study. Forests, 7, 65. https://doi.org/10.3390/f7030065

Williams, N. S. G., Schwartz, M. W., Vesk, P. A., McCarthy, M. A., Hahs, A. K., Clemants, S. E., ... McDonnell, M. J. (2009). A conceptual framework for predicting the effects of urban environments on floras. Journal of Ecology, 97(1), 4-9. https://doi.org/10.1111/j.13652745.2008.01460.x

Youngsteadt, E., Ernst, A. F., Dunn, R. R., \& Frank, S. D. (2016). Responses of arthropod populations to warming depend on latitude: Evidence from urban heat islands. Global Change Biology, 23, 1436-1447. https://doi.org/10.1111/gcb.13550

Zuur, A. F., leno, E. N., \& Elphick, C. S. (2010). A protocol for data exploration to avoid common statistical problems. Methods in Ecology and Evolution, 1, 3-14. https://doi.org/10.1111/j.2041-210X.2009.00001.x

Zuur, A. F., leno, E. N., Walker, N., Saveliev, A. A., \& Smith, G. M. (2009). Mixed effects models and extensions in ecology with R. New York, NY: Springer.

\section{SUPPORTING INFORMATION}

Additional supporting information may be found online in the Supporting Information section.

How to cite this article: Seress G, Sándor K, Evans KL, Liker A. Food availability limits avian reproduction in the city: An experimental study on great tits Parus major. J Anim Ecol. 2020;00:1-11. https://doi.org/10.1111/1365-2656.13211 